\title{
O programa de apoio a planos de Reestruturação e Expansão das Universidades Federais (REUNI): uma análise de seu processo de avaliação ${ }^{1}$
}

\author{
Program to Support the Plans for Restructuring and Expansion \\ of the Federal Universities System in Brazil (REUNI): \\ an analysis of its evaluation process
}

\author{
Edriene Cristine da Silva Santos Sales ${ }^{1}$ \\ ${ }^{1}$ Universidade Federal de Goiás \\ Goiânia | GO | Brasil. Contato: edri.cs2@gmail.com \\ http://orcid.org/0000-0002-1094-1416
}

\author{
Daniela Rosim ${ }^{2}$ \\ ${ }^{2}$ Programa de Pós-Graduação em Administração - PPGADM \\ Universidade Federal de Goiás | Faculdade de Administração, Ciências Contábeis e Economia \\ Goiânia | GO | Brasil. Contato: danielarosim@gmail.com \\ http://orcid.org/0000-0001-5882-9899
}

Vicente da Rocha Soares Ferreira ${ }^{3}$

${ }^{3}$ Programa de Pós-Graduação em Administração - PPGADM

Universidade Federal de Goiás | Faculdade de Administração, Ciências Contábeis e Economia Goiânia | GO | Brasil. Contato: vicenterochasf@gmail.com

http://orcid.org/0000-0002-1196-5778

\section{Sérgio Henrique Barroca Costa ${ }^{4}$}

${ }^{4}$ Programa de Pós-Graduação em Administração - PPGADM

Universidade Federal de Goiás | Faculdade de Administração, Ciências Contábeis e Economia Goiânia | GO | Brasil. Contato: sergio_barroca@ufg.br

http://orcid.org/0000-0001-7953-1290

Resumo: O presente estudo teve como objetivo levantar a produção científica em periódicos nacionais que abordasse o Programa REUNI por meio de um levantamento sistemático das publicações científicas, para identificar a existência de trabalhos sobre o tema avaliação de políticas públicas que tivesse como unidade de análise o REUNI. Foram selecionados 24 artigos de acordo com os critérios estabelecidos, no período de 2007 a 2016, envolvendo os tópicos, agrupados por critérios temáticos, os tipos de abordagem, as técnicas de pesquisa, além de aspectos temporais e autorais. Entre os temas categorizados, relacionados a políticas públicas, estão a avaliação, gestão institucional, inclusão, financiamento e socialização organizacional. Nos resultados, houve a predominância de trabalhos empíricos, de abordagem qualitativa e estudos descritivos. Também foi constatado que os autores e as revistas de maior destaque se situam nas regiões sudeste e sul do país. Concluiu-se que o REUNI foi uma importante ação governamental com o objetivo de desenvolvimento e aperfeiçoamento da educação superior e parece ser muito importante que a pesquisa avance sobre o tema para que se conheça melhor os resultados alcançados pela política.

Palavras-chave: Avaliação. REUNI. Educação superior.

\footnotetext{
${ }^{1}$ Este trabalho é uma versão expandida do artigo de mesmo título apresentado no EnAnpad 2017
} 
Abstract: This study aimed to raise and analyze the scientific production in national journals that approached the REUNI Program through systematic research of the scientific publications, to identify the existence of works on the subject of evaluation of public policies focused on REUNI. Twenty-four articles were selected according to the established criteria, between 2007 and 2016, involving topics, grouped by thematic criteria, types of approach, research tools, as well as temporal and authorial aspects. Among the topics categorized, related to public policies, are the evaluation, institutional management, inclusion, financing, and organizational socialization. In the results, there was a predominance of empirical studies, with a qualitative approach and descriptive studies. It has also been found that the authors and the most prominent journals are from southeastern and southern regions of the country. It was concluded that the REUNI was a decisive governmental action aimed at developing and improving higher education and it seems very important that the research advances on the subject so that the results achieved by the policy can be better understood.

Key words: Evaluation. REUNI. Undergraduate degree.

\section{DOI: http://dx.doi.org/10.1590/S1414-40772019000300006}

Este é um artigo publicado em acesso aberto sob uma licença Creative Commons https://creativecommons.org/licenses/by-nc/4.0/

Recebido em: 25 de outubro de 2018 Aprovado em: 23 de junho de 2019

\section{Introdução}

A educação superior ocupa posição de importância em todo o mundo e tem sido vista como propulsora do desenvolvimento para os países em ascensão, considerando-se, em especial, o fenômeno da globalização. A educação superior é também responsável pela promoção do conhecimento e, por consequência, da qualificação de uma população, o que contribui para o bem-estar coletivo e para o atendimento de demandas sociais e econômicas. Está diretamente vinculado à educação o desenvolvimento do pensamento e da consciência crítica, associados à construção e difusão dos saberes (DOURADO; CATANI; OLIVEIRA, 2004).

A educação superior tem um papel central no processo de desenvolvimento do Brasil, seja por meio do ensino em seus diferentes níveis, do desenvolvimento de pesquisas nas diversas áreas científicas, da extensão à sociedade de seu potencial e da sua expressão cultural. Todavia, permanece ainda hoje a necessidade de ampliação de seu alcance, dada a baixa parcela de jovens entre 18 e 24 anos cursando ensino superior no país (BRASIL, 2001).

As reformas educacionais realizadas nos governos Fernando Henrique Cardoso e Lula atuaram no sentido de ampliar as possibilidades de ingresso no ensino superior, ainda que com enfoques e ações diferenciadas. O governo de FHC recebeu críticas, no sentido de que a educação superior estava sendo 'mercadorizada', ao mesmo tempo em que o Estado diminuía sua responsabilidade com a Universidade. A reforma realizada naquele período (1995-2002) possibilitou um crescimento do ensino superior, todavia ocorreu prioritariamente na esfera do 
setor privado e manteve a realidade de elitização e seletividade étnica e racial no ingresso dos estudantes no ensino superior.

Já o governo Lula foi caracterizado como uma continuidade do anterior, em seu aspecto gerencialista (ANDRADE et al., 2011). Porém, nesse período (2003-2010), o Ministério da Educação definiu ações relacionadas à ampliação de vagas nas universidades públicas, ao planejamento do acesso para jovens com idade para ingresso nesse nível de ensino, e novos marcos de financiamento público da educação superior, considerando-se a relação ao PIB. A educação superior, no período, apresentava um cenário com perspectivas de políticas de expansão com qualidade e novos mecanismos de acesso e permanência a uma população historicamente não incluída no ensino superior (BITTAR; OLIVEIRA; LEMOS, 2011; DOURADO; CATANI; OLIVEIRA, 2004).

Naquele cenário, formulou-se o Programa de Apoio a Planos de Reestruturação e Expansão das Universidades Federais (REUNI), que foi a concretização de uma política pública educacional de nível superior, instituída pelo Governo Federal por meio do Decreto n. ${ }^{\circ}$ 6.096, de 24/04/2007 (BRASIL, 2007a). O programa foi proposto considerando as ações previstas no Plano de Desenvolvimento da Educação - PDE/2007 (BRASIL, 2007b), relacionadas aos objetivos propostos no Plano Nacional de Educação 2001-2011 - PNE/2001, aprovado pela Lei n. ${ }^{\circ}$ 10.172, de 9 de janeiro de 2001 (BRASIL, 2001). O REUNI teve como meta central a ampliação do acesso e da permanência dos estudantes na educação superior.

A adesão das universidades federais ao Programa à época de sua implementação, ainda que em graus diferentes, foi maciça, segundo relatório do primeiro ano do programa, elaborado pelo Ministério da Educação em 2009 ( BRASIL, 2009).

Diante da dimensão que alcançou essa política, é natural que se procure conhecer os resultados decorrentes das ações desse programa, uma vez concluído o período previsto para sua implementação (2008-2012). Ao se compreender o REUNI como uma política pública educacional de ensino superior, assim como sua avaliação e a forma como ela pode subsidiar ações governamentais na área tornam-se importantes. A avaliação é tida como uma ferramenta singular para a efetivação de transformações desejadas, não somente no que se refere ao contexto educacional, neste caso à educação superior, mas também ao social (DIAS SOBRINHO, 2010). Com base em tais argumentos, coloca-se a seguinte indagação: como os resultados da avaliação do REUNI têm sido analisados e discutidos pelos pesquisadores nacionais? Nesse sentido, o presente artigo teve como propósito realizar um levantamento bibliométrico com o tema REUNI, nos periódicos nacionais, a fim de identificar a existência de 
pesquisas que realizaram avaliações do programa, à luz da literatura de avaliação de políticas públicas.

É o que se realizou nas seções que seguem, que estão estruturadas de modo a discorrer primeiramente sobre políticas públicas educacionais no contexto da educação superior, com ênfase na importância da análise de políticas públicas; na seção seguinte, aborda-se o REUNI, enquanto um programa governamental voltado para o apoio à educação superior; a quarta seção discorre sobre os aspectos metodológicos, em que foram detalhados os critérios de seleção dos trabalhos analisados; na quinta seção, apresenta-se uma análise dos resultados obtidos; e, por fim, as considerações finais encerram o estudo.

\section{Políticas públicas e políticas públicas educacionais}

Preliminarmente à abordagem de políticas públicas no campo educacional, cabe aqui uma reflexão sobre a abrangência de políticas públicas e sobre a importância de sua análise. Uma política pública, segundo Secchi (2011), é uma diretriz elaborada para enfrentar um problema público e o estabelecimento de uma política pública; é o tratamento ou a resolução de um problema tido como coletivamente relevante. As políticas públicas no Brasil vieram a ser objeto de estudos recentemente, começando a ser abordadas a partir dos anos 1980, e, talvez até mesmo por isso, tais estudos ainda se mostram dispersos (TREVISAN; VAN BELLEN, 2008).

O campo de pesquisas em políticas públicas em geral tem vivenciado um despertar mais consistente no Brasil a partir dos anos 2000, tendo sido motivador de atividades de grupos de trabalho de instituições voltadas para essa área de estudos (como a Associação Nacional de PósGraduação e Pesquisa em Ciências Sociais - Anpocs) e, ainda, da criação de programas de pósgraduação interdisciplinares com foco em políticas públicas. Essa área vem experimentando um crescimento na instituição de linhas de pesquisa específicas em políticas públicas e tem conquistado interesse como objeto de pesquisa (FARIA, 2012).

As pesquisas, quanto à sua finalidade, podem ser classificadas em exploratória, descritiva, explicativa (ou inferencial) ou intervencionista. A pesquisa exploratória procura uma visão geral, uma maior familiaridade ou aprofundamento inicial sobre certo tema ou fato. Já a descritiva busca conhecer, caracterizar e interpretar a realidade, sem causar nenhuma interferência que possa modificá-la. A pesquisa explicativa objetiva explanar fatores que contribuem para determinado fenômeno, constituindo relação de causa e efeito. A 
intervencionista visa a explicar e ainda interferir na realidade estudada, com o intuito de sua modificação (MEDEIROS et al., 2011).

Ao discorrer sobre análise de políticas públicas, Lima e D’Ascenzi (2013) apontam para o modelo da abordagem sequencial, ou ciclo de políticas públicas, em que a política pública é separada em fases, a saber: formulação, implementação e avaliação. Na etapa da formulação, há a definição e a escolha dos problemas a receber a atenção e a intervenção do governo, a elaboração de soluções ou alternativas e a tomada de decisão, quanto ao problema identificado. $\mathrm{Na}$ fase da implementação, há a execução das decisões que foram tomadas na etapa anterior. E a avaliação diz respeito à fase de interrogação sobre o impacto da política. Ainda acerca da avaliação de políticas públicas, Trevisan e Van Bellen (2008) usam uma definição: é um mecanismo de melhoria no processo de tomada de decisão, com o intuito de garantir a obtenção de melhores informações, que possibilitem melhores decisões e prestação de contas sobre as políticas públicas.

A avaliação de política públicas somente foi se desenvolvendo na América Latina a partir da década de 1990, quando houve uma busca de fortalecimento do quesito avaliação na gestão governamental, o que se refletiu no desenvolvimento de sistemas de avaliação das políticas públicas, em diversas modalidades. Entretanto, a prática da avaliação ainda se mostra rudimentar em nosso país e se caracteriza basicamente em um instrumento de gestão governamental, com caráter eminentemente tecnicista e político (FARIA, 2005). Segundo o autor, a avaliação é utilizada em três dimensões: a instrumental - que se refere ao apoio dado às decisões e à busca de resolução de problemas; a conceitual - que seria a função educativa; e a simbólica - relativa ao uso político da avaliação.

Na opinião de Trevisan e Van Bellen (2008), os estudos brasileiros não têm dado muita atenção a métodos de investigação, mas seus conteúdos têm mencionado avaliação de resultados alcançados por políticas em andamento ou atualização de informações existentes sobre programas já consolidados. Segundo os autores, é necessário que haja uma mudança no foco dos estudos, deixando de lado a ênfase nos fracassos e preocupando-se um pouco mais com questões envolvendo a formulação e a implementação de políticas públicas, a identificação de variáveis que causam impactos sobre os resultados dessas políticas e meios que enfatizem o entendimento desses resultados.

Segundo Ramos e Schabbach (2012), a Constituição Federal de 1988, em artigo do título VI, correspondente a Tributação e Orçamento, estabeleceu o Plano Plurianual (PPA), que abrange quatro anos e contém as diretrizes, os objetivos e as metas da administração pública federal para as despesas de capital e para os programas de longa duração. O PPA tem um 
sistema de avaliação que contém um relatório anual de avaliação. Nesse sentido, de acordo com as autoras, o objetivo dessa medida foi o de assegurar que o processo de avaliação passasse a integrar a gestão dos programas, subsidiando a tomada de decisão, bem como disseminando a cultura de avaliação e garantindo sua utilização nas etapas de formulação e implementação das políticas e programas do governo, o que reforça a importância da avaliação de políticas públicas.

O propósito original da avaliação seria melhorar a qualidade das decisões que são tomadas em âmbito governamental e buscar meios de garantir que os objetivos traçados pelas políticas públicas possam ser amplamente alcançados. Depreende-se daí a importância da análise de políticas públicas, uma vez que por meio da avaliação pode-se utilizar um singular instrumento de coleta de informações e dados, os quais, de posse por quem detém o poder de decisão, podem contribuir com a busca do alcance das melhores ações, com vistas ao êxito de uma política pública, desde sua formulação, execução, até a prestação de contas (FARIA, 2005).

Conforme Calderón e Borges (2013), a pesquisa e o estudo quanto à avaliação das políticas públicas educacionais no país ainda são ações que estão sendo trabalhadas e que aos poucos vêm se consolidando na comunidade acadêmico-científica. Tratando-se de ensino superior, sua trajetória de avaliação, no sentido de uma estrutura de um modelo de avaliação nacional, tem início nos anos 1990, tendo sido impactada, ainda, pelas correntes paradigmáticas da administração pública vigente, que traziam o teor político e social de seu contexto, segundo a relação entre a avaliação e a regulação da educação superior (MORAES; AMBONI; KALNIN, 2017). Foi também a partir desse período que a avaliação da educação começou a tomar repercussão social, a partir da Reforma do Estado, implantada em 1995 (ROTHEN et al., 2015). Segundo Polidori (2009), as últimas décadas de avaliação da educação superior no Brasil têm apresentado mudanças em seu formato, em especial quanto à sua concepção, passando de uma avaliação totalitária, focando em ranqueamento institucional, para uma que respeita as diversidades e as especificidades das Instituições de Educação Superior (IES).

Dessa forma, este estudo pretende unir-se aos já realizados, no âmbito da educação superior, uma vez que sua atenção está voltada para conhecer o que a pesquisa tem produzido sobre o REUNI e o que pode ser identificado como resultados advindos desse programa. Na próxima seção, serão abordados estudos envolvendo análises do referido programa educacional. 


\section{O REUNI e a expansão das Universidades Federais}

As informações levantadas pelo PNE em 2001 apontavam para uma porcentagem insatisfatória de jovens egressos do ensino médio que iniciavam seu curso de graduação: somente $12 \%$ dos jovens de 18 a 24 anos conseguiam acesso à educação superior. Diagnósticos e análises baseados em dados estatísticos relativos às universidades brasileiras levantavam questionamentos sobre o número de vagas existentes nas instituições públicas de ensino superior e as altas taxas de evasão da educação superior, o que gerou, em 2006, uma movimentação de insatisfação com o formato de ensino adotado (ANDRADE et al., 2011).

É um desafio para o Brasil a situação de baixa qualidade do sistema educacional, que se caracteriza por não atender às demandas sociais de inclusão e qualificação profissional (CABRAL et al., 2011). Seria desejável que a Universidade estivesse ao alcance de todos os jovens aptos a cursá-la, ao terem concluído o ensino médio. A proposta surgida para se contrapor a esse quadro, depois de uma série de estudos, debates e seminários em várias instâncias das comunidades acadêmicas e segmentos da sociedade, materializou-se na publicação do Decreto n. ${ }^{\circ} 6.096$ (BRASIL, 2007a), o qual instituiu o Programa REUNI, que teve como objetivo a ampliação do acesso e permanência na educação superior, no nível de graduação, por meio do melhor aproveitamento da estrutura física e de recursos humanos existentes nas universidades federais. Tal programa também teve como meta global a elevação gradual da taxa de conclusão média dos cursos de graduação presenciais para noventa por cento e o aumento da relação de alunos de graduação em cursos presenciais por professor para dezoito, ao final de cinco anos (CABRAL et al., 2011).

A adesão das universidades ao programa seria facultativa, por meio de um termo de compromisso e um acordo de metas. A liberação de financiamento para a instituição participante do programa estaria condicionada ao cumprimento das metas estabelecidas no acordo firmado. Os recursos seriam disponibilizados à medida que os planos de reestruturação fossem elaborados e apresentados. Na visão de pesquisadores, estaria caracterizado aí o predomínio das finanças sobre a educação, característica essa oriunda da administração pública gerencial, devido a uma aparência participativa em nível de discurso, porém centralizadora em termos de poder decisório (ANDRADE et al., 2011).

Em linha com esse pensamento, Martoni e Ferraz (2013) discorreram que a reestruturação das Instituições Federais de Ensino Superior (IFES) tornou-se uma necessidade, porém os planos elaborados pelas IFES e encaminhados ao Ministério da Educação, em 
atendimento aos acordos firmados com base nas metas quantitativas do REUNI, poderiam comprometer a formação qualitativa oferecida pelas instituições.

Na visão de Oliveira e outros (2014), as IFES, executoras do programa REUNI, por integrarem o sistema de ensino superior, são essenciais para o desenvolvimento econômico do país. Como um ente público, sua gestão deveria ser orientada pelos princípios da eficiência e produtividade no uso dos recursos que the foram disponibilizados pelo governo federal. Assim, as IFES precisariam ser avaliadas pela capacidade de atendimento às demandas e exigências dos usuários dos serviços que por elas são prestados e deveriam, portanto, ser capazes de dar uma resposta satisfatória aos anseios da população, contribuindo para a construção de uma sociedade mais democrática, justa, solidária e inclusiva, bem como para uma formação técnicocientífica de qualidade dos seus egressos, condizente com as exigências do mundo de trabalho contemporâneo.

Para Barbosa (2015), apesar da existência de estudos pontuais sobre o REUNI, ainda é escasso o número de publicações que façam uma avaliação geral do impacto dessa política pública. Segundo a autora, os estudos de caso disponíveis indicam alguns avanços, principalmente relacionados à criação de cursos e à contratação de mais professores, porém não tratam dos problemas e dificuldades encontrados pelas instituições para que o REUNI se tornasse uma política de democratização do ensino superior. Ou seja, seria interesse então destinar atenção não só aos resultados finais, mas também à compreensão do processo de desenvolvimento do programa, identificando seus obstáculos, seus conflitos e suas limitações.

Nesse sentido, Lima e Machado (2016) entendem que, na avaliação dos resultados alcançados pelo REUNI, será preciso considerar que as dificuldades cotidianas confrontadas pelas IFES não são exclusivamente associadas ao referido programa. Para essa avaliação, fazse necessário, ainda, levar em conta a história, particularidades de cada região, especificidades, etapas de desenvolvimento, tamanho e cultura organizacional de cada instituição que optou por aderir ao REUNI. Em todas elas, houve uma intensificação do trabalho conjunto de docentes e técnico-administrativos, com relação à oferta do ensino de graduação, bem como às demais metas estabelecidas.

Borges e Aquino (2012) concluem, a partir do relatório do primeiro ano do programa e identificadas algumas limitações, que é necessária uma avaliação da qualidade de ensino e da efetivação da função social da universidade, propondo a busca de inovação pedagógica, a partir do diálogo com a sociedade. Nessa linha, os autores entendem que são numerosos os desafios político-sociais que envolvem a realidade da educação superior no país e que a dimensão 
quantitativa deve caminhar juntamente com a qualitativa, no que se relaciona aos aspectos da vida acadêmica das instituições e aos processos pedagógicos da formação universitária.

A partir do que foi discutido nesta seção, realizou-se esta pesquisa sobre a avaliação de políticas públicas de Faria (2005) focada nas dimensões: instrumental, conceitual e simbólica, explicados na seção anterior, para avaliar, categorizar e discutir as publicações do programa REUNI levantadas neste estudo, consoante os aspectos metodológicos descritos na seção a seguir.

\section{Aspectos Metodológicos}

A fim de estudar a produção científica sobre avaliação do programa REUNI enquanto política pública, foi realizado levantamento de artigos científicos para estudo bibliométrico nas bases de periódicos Capes e Spell e sítio de publicações da ANPAD. A escolha dessas bases se refere ao fato de que o interesse deste trabalho foi conhecer o atual estágio de desenvolvimento da pesquisa em avaliação no campo da gestão, sem deixar de reconhecer que existem outras bases de pesquisa em avaliação como é o caso da ANPED. Os critérios utilizados para a montagem das strings de busca dos artigos em cada uma das máquinas de busca foram: (a) palavra-chave: REUNI; (b) ano de publicação: 2007 a 2016; (c) campo: título ou resumo ou qualquer, conforme as opções de cada base, dando sempre preferência para o mais amplo.

A palavra-chave 'REUNI' foi escolhida por ser o objeto do estudo e, por ela, todos os artigos referentes a esse programa de política pública são filtrados. Os anos de publicação entre 2007 a 2016 foram assim determinados, porque foi o período em que o programa esteve ativo e que este artigo foi produzido. Por fim, quanto ao campo escolhido, deu-se sempre preferência para o mais amplo, para poder filtrar a maior quantidade possível de artigos.

Na base Periódicos Capes, em busca avançada, no campo "título", utilizou-se a palavra REUNI; em "data de publicação", selecionou-se: últimos 10 anos; e em "tipo de material", assinalou-se a opção artigos. Com essas opções, foram encontrados dezessete artigos, sendo que, destes, quatro não tratavam do assunto pesquisado, mas referiam-se a outras palavras, como por exemplo "REUNIão", e foram, portanto, ignorados. Na base Spell, opção "pesquisa avançada", utilizou-se o filtro "tipo do documento" para as consultas pretendidas com a palavra REUNI; "período de publicação": de 2007 até 2016; "tipos de documentos": artigo, sendo que foram encontrados dez artigos, porém seis deles não se referiam ao tópico do estudo e foram desprezados. 
No sítio de publicações da ANPAD, no campo "sua pesquisa", foi inserido o termo REUNI e, quando houve o direcionamento para a pesquisa "buscar por", escolheu-se "título" e inseriu-se a palavra-chave REUNI. Como resultado, foram encontrados seis artigos. Desse total, somente três reportavam-se ao assunto de interesse desta pesquisa. Nesse sítio, não havia a possibilidade de filtros com mais de uma opção de busca, o que então não possibilitou a combinação das palavras-chave para a consulta. Tentou-se então inserir no campo título outras palavras-chave que pudessem trazer alguma relação com o tema proposto, como reestruturação, expansão e política educacional, porém o retorno não se mostrou efetivo e os resultados foram nulos.

Nas tabelas 1 e 2 a seguir, estão resumidos os demais termos e palavras-chaves utilizadas, com variação do "campo de busca", na tentativa de ampliar as possibilidades de retorno da consulta. Ao final, foram encontrados 40 artigos, no entanto, ao excluírem-se os artigos repetidos, o total exato ficou em 24 artigos selecionados para análise do presente trabalho.

Tabela 1 - Consulta de artigos com combinação de palavras-chave.

\begin{tabular}{c|c|c|c|c|c|c|c|c|c}
\hline & REUNI & Avaliação + & Reestruturaçãa & Impacto + & Análise + & Estudo + & Política + & Educacional & Total \\
\hline Capes & 13 & 0 & 5 & 1 & 2 & 5 & 1 & 1 & 28 \\
\hline Spell & 4 & 0 & 2 & 0 & 1 & 1 & 1 & 0 & 9 \\
\hline Total & & & & & & & & & 37 \\
\hline
\end{tabular}

Fonte: dados da pesquisa, 2017.

Tabela 2 - Consulta publicações ANPAD com variação de palavras-chave no campo título.

\begin{tabular}{c|c|c|c|c|c}
\hline$\#$ & REUNI & Reestruturação & Expansão & Política Educacional & Total \\
\hline Publicações & 3 & 0 & 0 & 0 & 3 \\
\hline
\end{tabular}

Fonte: dados da pesquisa, 2017.

\section{Apresentação e análise dos resultados}

A partir dos critérios adotados, concluídas a escolha e a categorização dos temas, foram selecionados 24 artigos, oriundos das bases dos Periódicos Capes e do Spell e sítio de publicações da ANPAD. Após uma primeira coleta, não foram identificados artigos que tivessem em seu título o tópico avaliação. Dessa forma, foi analisado o material encontrado, com o objetivo de identificar se contemplava o tema de avaliação do REUNI enquanto uma política educacional de ensino superior. Com isso, além da temática envolvendo avaliação, puderam ser identificados outros temas nos trabalhos estudados, a partir da realização de uma categorização que considerou tanto os títulos, como os objetivos e considerações finais dos 
artigos. Assim, os estudos abordaram também gestão institucional, inclusão, financiamento e socialização organizacional, relacionados ao referido programa.

É importante destacar que no tema avaliação foram incluídos estudos que realizaram análises não só especificamente da política pública, mas também da percepção dos pesquisadores ou dos gestores quanto às mudanças trazidas pelo programa, bem como uma análise dos seus impactos ou resultados, além da análise das ações institucionais e da gestão, frente a uma nova postura do Estado com relação às suas políticas educacionais. Optou-se por não fazer distinção entre avaliação e análise de política pública no presente estudo porque observa-se ainda estudos realizados no campo da gestão que aproximam esses conceitos, embora sejam diferentes, pois a avaliação é uma etapa do policy cicle (SERAFIM; DIAS, 2012). Assim, o processo de avaliação está centrado na apreciação de resultados das políticas enquanto a análise de política, como observam Serafim e Dias (2012), deve ser entendida como um conjunto de observações que envolve todo o ciclo da política, que engloba as etapas de identificação de um problema a ser enfrentado pela política, da definição da agenda, da formulação da política própria dita, do processo de implementação e, por último, mas isoladamente, do processo de avaliação.

Procurou-se identificar, neste estudo, o tipo de abordagem dos artigos, bem como os aspectos metodológicos adotados, optando-se por classificá-los segundo sua finalidade, suas técnicas de pesquisa e seu período de publicação. Também foram analisadas as revistas em que foram publicados, a quantidade de autores por artigo e as instituições a que se vinculavam os autores. $\mathrm{O}$ intuito foi o de conhecer as instituições mais dedicadas ao tema da avaliação do REUNI e identificar se o tema despertava interesse em pesquisadores em várias instituições, refletindo o modo como é desenvolvido o seu trabalho: se local ou por meio de redes de pesquisa.

Quanto à abordagem, foi verificado se foram utilizados mais tipos quantitativo, qualitativo ou misto, isto é, quantitativo combinado com qualitativo. Nesse sentido, foram identificados dezesseis artigos que usaram uma abordagem qualitativa, ou seja, $66 \%$ do total. Dos 24 artigos estudados, 21\% (cinco) utilizaram métodos quantitativos e qualitativos simultaneamente e somente um optou pela abordagem quantitativa, reforçando a linha de preferência qualitativa ao se desenvolver o tema de políticas públicas.

No presente estudo, consoante classificação utilizada por Medeiros et al. (2011) quanto à finalidade das pesquisas, verificou-se primeiramente que a predominância dos artigos é de natureza empírica, em que somente dois dos 24 artigos estudados seguem a linha teórica, o que está intimamente relacionado com a área de atuação da avaliação, que trabalha com os 
resultados advindos das experiências desenvolvidas. Identificou-se ainda a ocorrência de maior número de artigos de pesquisa descritiva ( $46 \%$ ou 11 artigos), seguida da exploratória (29\% ou 7) e $17 \%$ de estudos de casos (4 artigos), em que os autores afirmam ser sua pesquisa tanto de finalidade exploratória quanto descritiva. Podem ser identificados como explicativos dois artigos, $8 \%$ do total.

No que se refere às técnicas de pesquisa utilizadas, identificou-se a utilização das técnicas de pesquisa documental, revisão bibliográfica, estudo de caso, observação, entrevistas, levantamentos, questionários e técnicas estatísticas, havendo a possibilidade de um mesmo artigo utilizar mais de uma técnica. A pesquisa documental foi a técnica predominante, tendo sido citada por seus autores em dez dos 24 artigos. A revisão bibliográfica foi mencionada em cinco artigos, assim como as entrevistas. O uso de questionários está presente em quatro artigos, mesmo número que menciona o uso de técnicas estatísticas. Estudo de caso foi abordado em duas situações e a observação, em um artigo.

Quanto ao ano de publicação dos artigos, verificou-se que somente no ano de 2009 estudos a respeito do programa REUNI começaram a ser publicados, mais especificamente, sobre a avaliação da expansão da educação superior brasileira, com a publicação de apenas um artigo. Tal constatação encontra-se em linha com o que discorrem Calderón e Borges (2013), quando abordam que as pesquisas em avaliação de políticas públicas ainda vêm se estruturando e se desenvolvendo na comunidade acadêmico-científica brasileira.

Os resultados demonstram que a atenção ao programa REUNI veio a se intensificar no ano de 2011, com cinco publicações. Tal fato coincide com o término do prazo de implementação do programa. Os números de publicações repetem os de 2011 nos anos de 2013, 2014 e 2015 e tal fato também coincide com a data de encerramento do programa REUNI no ano de 2012, o que pode ter motivado e explicado o investimento na produção de pesquisas científicas, abordando a avaliação do programa governamental. Em 2012, foram duas publicações e uma em 2016. A figura a seguir traz a ilustração destas informações. 
Figura 1 - Número de publicações de artigos abordando o tema REUNI, conforme o ano.

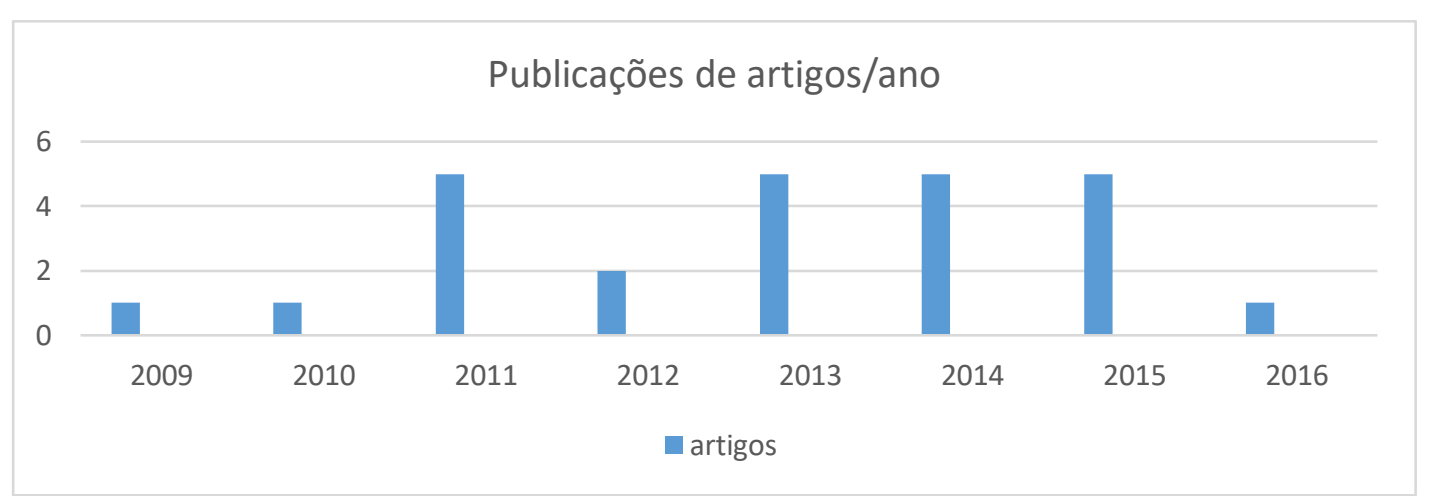

Fonte: dados da pesquisa, 2017.

O estudo revela ainda que as revistas que mais se voltaram para o tópico do REUNI foram a Revista Gestão Universitária na América Latina - GUAL/SC, com quatro artigos publicados, e as publicações do Encontro Nacional da ANPAD (Associação Nacional de PósGraduação e Pesquisa e Administração/RJ) - EnANPAD, com dois artigos. Os outros dezoito artigos que compõem a base de análise deste trabalho foram publicados cada um por periódicos diferentes.

Pela análise da localização dos periódicos, percebe-se que a abordagem do tema do REUNI, e consequentemente sua avaliação, tem sido contemplada por revistas que se concentram nas regiões sul, com onze publicações, e sudeste, com nove. A maior concentração de publicações de artigos nessa área repousa sobre as revistas de Santa Catarina, com sete artigos publicados, especialmente a revista GUAL. A figura 2 a seguir ilustra estes dados.

Figura 2 - Quantidade de artigos publicados em revistas por regiões

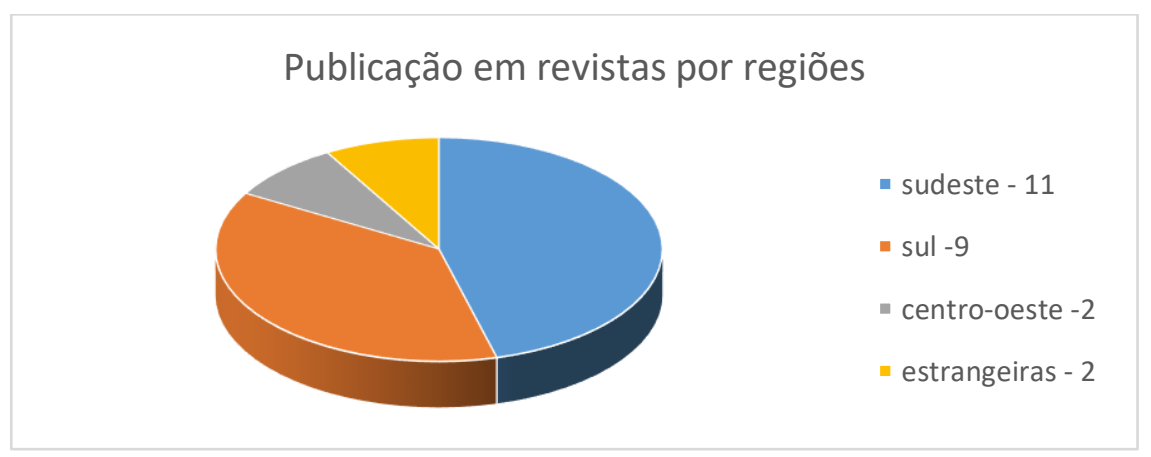

Fonte: dados da pesquisa, 2017.

Ao analisar o quesito autores dos artigos, percebe-se que a preferência dos pesquisadores está no desenvolvimento de artigos por dois e três autores. Nove artigos foram 
escritos em coautoria por dois pesquisadores e em oito a escolha foi desenvolvê-los com três autores. Três artigos foram escritos por somente um pesquisador e outros três, por quatro autores. Em somente um artigo houve a cooperação entre seis autores, sendo quatro de uma mesma instituição, o que leva a pensar no desenvolvimento de trabalhos em um núcleo de pesquisa local em parceria com outras instituições de ensino. A tabela 3 demonstra essas informações mais detalhadamente.

Tabela 3 - Distribuição de artigos por autores

\begin{tabular}{c|c|c}
\hline Número de autores & Quantidade de artigos & Porcentagem \\
\hline 1 & 3 & $12,5 \%$ \\
\hline 2 & 9 & $37,5 \%$ \\
\hline 3 & 8 & $33,4 \%$ \\
\hline 4 & 3 & $12,5 \%$ \\
\hline 5 & 0 & 0 \\
\hline 6 & 1 & $4,1 \%$ \\
\hline
\end{tabular}

Fonte: dados da pesquisa, 2017.

Nos trabalhos publicados com dois autores, foi maior o número de artigos composto por pesquisadores da mesma universidade, $55,6 \%$, o que remete ao entendimento de que as relações são mais comuns no âmbito das próprias instituições. Todavia, foi bem próximo o número de artigos publicados com dois autores que não pertenciam à mesma instituição, 44,4\%, porém notou-se que na metade desses casos eles eram do mesmo estado, o que pode sugerir a existência de grupos de pesquisa regionais.

Nas pesquisas com três autores, a maioria era de uma mesma instituição, 62,5\%, remetendo à ideia de que o campo de pesquisa em rede em níveis regionais, nacionais e internacionais ainda pode ser mais bem explorado pelos pesquisadores. Identificou-se a existência de duplas em cada instituição, em dois artigos dos três contendo quatro autores, sendo que em um desses artigos as instituições eram de um mesmo estado, podendo caracterizar uma rede regional de pesquisa.

Quanto à análise de artigos por instituições, buscou-se identificar se alguma sugeriu uma maior dedicação com a área de avaliação de políticas públicas, e em especial a educacional. Como método de identificação, no caso de mais de um autor pertencer a uma mesma instituição, foi computado como uma única publicação, para se evitar a duplicação de contagem de artigos. A instituição foi computada mais de uma vez, quando se referia a artigos diferentes. Dessa forma, as instituições que mais publicaram artigos nessa área de estudos foram a Universidade Federal de Minas Gerais e a Universidade Federal de Santa Catarina, ambas com três artigos publicados. Tal fato leva à conclusão de que as produções que envolvem a avaliação do REUNI 
como uma política pública educacional concentram-se nas regiões sul e sudeste do país. Essa ideia se reforça, quando se nota que das seis instituições com dois artigos publicados, três são do estado de Minas Gerais.

A figura e a tabela que seguem detalham as instituições com publicações por região e por suas produções científicas.

Figura 3 - Número de instituições com publicações por região

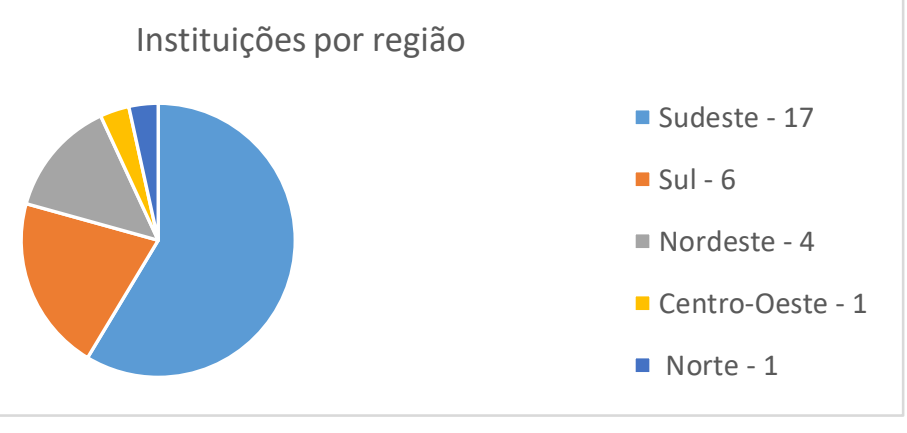

Fonte: dados da pesquisa, 2017.

Tabela 4 - Publicações científicas das instituições

\begin{tabular}{|c|c|}
\hline Instituição & Número de \\
\hline Universidade Federal de Minas Gerais & 3 \\
\hline Universidade Federal de Santa Catarina & 3 \\
\hline Instituto Federal de Educação, Ciência e Tecnologia do Sul de Minas Gerais & 2 \\
\hline Universidade Federal de Lavras & 2 \\
\hline Universidade Estadual do Piauí & 2 \\
\hline Universidade Federal de Pelotas & 2 \\
\hline Centro Universitário UMA/MG & 2 \\
\hline Universidade Federal do Rio Grande do Norte & 2 \\
\hline Instituto Federal de Educação, Ciência e Tecnologia do Norte de Minas Gerais & 1 \\
\hline Universidade Federal de Sergipe & 1 \\
\hline Universidade Federal de Ouro Preto & 1 \\
\hline Universidade do Oeste de Santa Catarina & 1 \\
\hline Universidade Federal do Ceará & 1 \\
\hline Faculdade FIA de Administração e Negócios/SP & 1 \\
\hline Devry Brasil & 1 \\
\hline Universidade Federal do Paraná & 1 \\
\hline Faculdade Salesiana do Espírito Santo & 1 \\
\hline Universidade Federal do Espírito Santo & 1 \\
\hline Universidade Federal de Viçosa & 1 \\
\hline Instituto Federal do Sudeste de Minas Gerais & 1 \\
\hline Universidade Federal de Pernambuco & 1 \\
\hline Universidade Federal do Triângulo Mineiro & 1 \\
\hline Universidade de Uberaba & 1 \\
\hline Universidade Federal do Rio Grande do Sul & 1 \\
\hline Universidade Federal de São João del-Rei & 1 \\
\hline Instituto de Pesquisas e Estudos em Administração Universitária (INPEAU)/SC & 1 \\
\hline Universidade Federal do Rio de Janeiro & 1 \\
\hline Universidad Carlos III de Madrid & 1 \\
\hline Universidade Federal de São Carlos & 1 \\
\hline
\end{tabular}




\begin{tabular}{c|c}
\hline & Número de \\
\hline Ministério do Planejamentção, Orçamento e Gestão & 1 \\
\hline
\end{tabular}

Fonte: dados da pesquisa, 2017.

A maior porcentagem dos artigos concentrou-se no tema avaliação, dezesseis dos 24 estudados. Quatro artigos foram classificados como gestão institucional, pois estudaram a postura e as características da gestão frente aos desafios do REUNI, buscando conhecer se o programa exerceu influência na eficiência operacional das IFES. Foram identificados dois trabalhos que abordaram o tema da inclusão em seus estudos: um aborda a preocupação com estudantes trabalhadores que não têm acesso a cursos de período integral e outro que aborda a instituição de programas específicos para inclusão social, voltados para estudantes oriundos da rede pública de ensino, e inclusão racial, dirigidos a estudantes autodeclarados negros. Os outros dois temas contemplaram um artigo cada um, discorrendo sobre financiamento do ensino superior e sobre socialização organizacional. A tabela 5 sumariza a categorização dos temas encontrados.

Tabela 5 - Temas abordados nos artigos estudados

\begin{tabular}{l|c|c}
\hline \multicolumn{1}{c|}{ Tema } & Artigos & Porcentagem \\
\hline Avaliação & 16 & $66,66 \%$ \\
\hline Gestão institucional & 4 & $16,66 \%$ \\
\hline Inclusão & 2 & $8,34 \%$ \\
\hline Financiamento do ensino superior & 1 & $4,17 \%$ \\
\hline Socialização organizacional & 1 & $4,17 \%$ \\
\hline Total & 24 & $100 \%$ \\
\hline
\end{tabular}

Fonte: dados da pesquisa, 2017.

Estes resultados, que apontam para um prevalecente uso do tema avaliação nos artigos estudados, reportam-nos à importância deste tópico e também às considerações de Faria (2005), quando aborda o uso da avaliação em seu sentido original, qual seja melhorar a qualidade das decisões e garantir a maximização do alcance dos objetivos definidos pelas políticas públicas.

Resgatando-se, ainda, as considerações de Faria (2005), em que a avaliação de políticas públicas é utilizada em três dimensões: a instrumental, a conceitual e a simbólica, entende-se que os artigos pesquisados podem ser relacionados nesta classificação. Assim, identificou-se que nove artigos podem ser incluídos na dimensão instrumental; onze podem ser considerados de caráter conceitual e quatro, simbólicos. Ao se catalogar os temas identificados nos estudos pesquisados na perspectiva dessas dimensões, adotou-se a predominância da característica, 
mesmo para aqueles que se identificaram em mais de uma dimensão. Assim, ao ser classificado em uma dimensão por seus traços predominantes, o artigo seria excluído das outras. Foram utilizados os critérios de predominância e exclusividade. Nesse sentido, constatou-se um certo equilíbrio entre os artigos identificados como de dimensão conceitual, onze, e de instrumental, nove, sendo a dimensão simbólica relacionada a quatro artigos. Quanto aos temas categorizados em relação às dimensões, a tabela abaixo demonstra a divisão das pesquisas.

Tabela 6 - Temas abordados em relação às dimensões segunda Faria (2005)

\begin{tabular}{|c|c|c|}
\hline Dimensão & Temas & Artigos \\
\hline \multirow{4}{*}{ Conceitual } & Avaliação & 9 \\
\hline & Socialização organizacional & 1 \\
\hline & Gestão institucional & 1 \\
\hline & Subtotal & 11 \\
\hline \multirow{4}{*}{ Instrumental } & Avaliação & 6 \\
\hline & Gestão institucional & 2 \\
\hline & Inclusão & 1 \\
\hline & Subtotal & 9 \\
\hline \multirow{5}{*}{ Simbólica } & Avaliação & 2 \\
\hline & Financiamento do ensino superior & 1 \\
\hline & Inclusão & 1 \\
\hline & Subtotal & 4 \\
\hline & Total & 24 \\
\hline
\end{tabular}

Fonte: dados da pesquisa, 2017.

A princípio, esperava-se que a dimensão instrumental fosse a mais expressiva, ao se pensar na natureza do Programa REUNI, dadas as diretrizes pré-definidas que sugeriam metas objetivas. Todavia, o certo equilíbrio entre as dimensões conceitual e instrumental leva à reflexão de que, sendo as universidades brasileiras campos propícios para um ambiente de debates e discussões, houve um espaço propício para uma maior reflexão crítica em relação ao modelo gerencialista.

Ao analisar a percepção - se positiva ou negativa - do programa nos trabalhos publicados, verificou-se que onze apresentavam aspectos positivos resultantes das pesquisas realizadas, destacando dentre eles: a) a inclusão, com oportunidade a pessoas negras, de classes economicamente desfavorecidas e egressas de escola pública; b) a expansão de vagas; c) a criação de cursos; e d) a ampliação da produção científica. Dez dos estudos mencionavam resultados que não concluíam para aspectos nem positivos, nem negativos, mas apontavam preocupações com a qualidade dos serviços apresentados pelas instituições, sob a observação de que ainda deveriam ser aprofundadas as investigações sobre as ações do programa. Por fim, três dos estudos mencionavam aspectos negativos, afirmando que o programa se voltava prioritariamente para o atendimento das orientações do mercado de capital, que visa 
essencialmente o lucro, caracterizando-se em uma natureza de quase-mercado, e preocupandose em menor escala com a função acadêmica da educação superior.

Pode-se depreender dos dados deste trabalho que o investimento na educação superior pública pode promover a ampliação do acesso a grupos sociais antes não contemplados, e aperfeiçoar um processo de socialização educacional desejado para uma parcela bem maior dos jovens estudantes brasileiros. Além disso, pode, ainda, contribuir para o desenvolvimento regional por meio da interiorização das universidades, que as aproxima de espaços e populações antes excluídas do ensino, da pesquisa e da produção científica, em todas as áreas do conhecimento.

Os resultados encontrados neste trabalho demonstram a necessidade de continuidade de pesquisas sobre o tema da expansão das universidades federais, a fim de buscar mais respostas para a discussão sobre os impactos do programa para a sociedade como um todo e para a educação superior de qualidade no Brasil em particular.

\section{Considerações finais}

A educação superior exerce importante influência no desenvolvimento de uma nação, ao possibilitar a criação de conhecimentos nas diversas áreas da ciência, capazes de promover novos pensamentos, descobertas inovadoras, formas mais eficazes de produção, tecnologia de ponta, entre outros. O Programa REUNI (BRASIL, 2007a) deu impulso a uma nova fase da educação superior brasileira, ao propor ações de expansão do ensino superior.

O tempo de duração do programa foi de cinco anos, sendo que, após a publicação do decreto, instituído em abril de 2007, algumas instituições definiram suas metas para vigorarem a partir do segundo semestre daquele ano, enquanto outras concentraram suas ações a partir do primeiro semestre de 2008. Por isso, considera-se, de modo geral, o período de 2008 a 2012 como duração do REUNI, razão pela qual este estudo limitou-se a investigar a produção científica sobre o REUNI que abarcassem o recorte temporal de 2007 a 2016, incluindo os quatro anos posteriores à implementação do programa, com vistas a pesquisar as publicações que se dedicaram à sua avaliação.

De igual forma, das três fases do ciclo de políticas públicas - formulação, implementação e avaliação -, o foco deste estudo repousa na avaliação do Programa REUNI, enquanto uma medida adotada pelo governo federal, parte de uma política pública de educação superior. Assim, não foram consideradas informações sobre a formulação e a implementação do programa. Estas etapas, inclusive, são sugestivas como objeto de futuras investigações. 
A realização desta pesquisa possibilitou algumas observações importantes, conforme exposto a seguir.

a) O declínio das publicações a partir de 2016 sugerem que o desinteresse no tema pode ser oriundo do encerramento do programa em 2012, sendo que os impactos decorrentes de sua implementação, após quatro anos, não seriam mais tão significativos. Todavia, a continuidade de análises científicas sobre os resultados alcançados pelo programa poderia ser uma fonte importante de informações, com potencial de subsidiar novos pleitos em defesa da educação superior no país.

b) A centralidade de revistas e instituições que abordaram o tema do REUNI nas regiões sudeste e sul refletem a carência de uma maior interação entre pesquisadores em âmbito nacional, dada a concentração regional de estudos voltados para a avaliação de programas e políticas educacionais. Emerge desse fato a sugestão de estudos futuros que invistam no fortalecimento de redes de pesquisa inter-regionais.

c) Reflexo ainda da observação anterior, foi identificada pouca continuidade de estudos dedicados à avaliação do programa por parte dos autores, tendo ocorrido na maioria das vezes estudos pontuais.

d) Os temas mais abordados nos artigos estudados apontam a avaliação em primeiro lugar, o que denota a existência de um campo fértil para a continuidade de estudos nessa área, envolvendo a análise de políticas públicas educacionais. A literatura impulsiona a dedicação de esforços na pesquisa científica em torno da avaliação de políticas públicas, uma vez que esta pode constituir-se em um importante instrumento de gestão, capaz de auxiliar no aperfeiçoamento do processo de tomada de decisão com relação a políticas públicas e na obtenção de informações relevantes para decisões mais eficazes e prestações de contas mais efetivas, no intuito do fortalecimento de estudos envolvendo políticas públicas no país.

Assim, conclui-se que a avaliação do Programa REUNI como uma política pública educacional encontra espaço para discussão, uma vez que, diante do encerramento do programa em 2012, faz-se necessário encontrar alternativas para traçar futuros rumos para a educação superior brasileira. Conforme identificado neste estudo, os benefícios oriundos da implementação do programa trouxeram conquistas em termos de inclusão, em especial de estudantes negros e oriundos de escola pública, aumento de vagas e de cursos, além do aumento da produção científica.

Partindo da análise dos temas emergentes dos artigos estudados na presente pesquisa, em que o segundo mais abordado foi o tema da gestão institucional, sugere-se como estudos futuros uma aproximação entre a área de Administração e a de Educação, mais especificamente a gestão da educação, no intuito de que os programas de pós-graduação voltados para a Administração, em especial a Administração Pública, possam realizar pesquisas nessa área e dessa forma colaborar com o avanço de práticas administrativas inovadoras que tragam diferentes expectativas para o ensino superior. 
O Programa REUNI foi uma grande ação governamental envolvendo a educação superior, com metas de ampliação de acesso e de permanência nas instituições de ensino. Todavia, as posteriores restrições orçamentárias oriundas das medidas do governo central caracterizam-se como grandes desafios para os gestores das Universidades em nosso país, na busca da manutenção da educação superior pública, gratuita e de qualidade. A ausência de perspectivas claras em benefício da educação superior por parte do governo federal é um motivador para que mais discussões sejam abertas, a partir dos resultados encontrados em futuras pesquisas, a fim de que novas propostas para a defesa e o desenvolvimento da educação superior possam ser elaboradas.

\section{Referências}

ANDRADE, D. C. T. de et al. A gestão pública e o Reuni: entre o social e o gerencial. Revista da Universidade Vale do Rio Verde, Rio Verde, v. 9, n. 2004, p. 154-170, 2011.

BARBOSA, M. L. de O. Destinos, escolhas e a democratização do ensino superior. Política \& Sociedade, Florianópolis, v. 14, n. 31, p. 256-283, 2015.

BITTAR, M.; OLIVEIRA, J. F. de; LEMOS, J. Reforma da educação superior a partir dos anos 1990 e suas repercussões na região Centro-Oeste. Revista Teoria e Prática da Educação, Maringá, v. 14, n. n. 2, p. 123-137, 2011.

BORGES, M. C.; AQUINO, O. F. Educação superior no Brasil e as políticas de expansão de vagas do Reuni : avanços e controvérsias. Educação: teoria e prática, Rio Claro, v. 22, n. 39, p. 117-138, 2012.

BRASIL. Ministério da Educação. Lei n. ${ }^{\circ}$ 10.172, de 9 de janeiro de 2001. Aprova o Plano Nacional de Educação. Brasília, DF: Ministério da Educação, 2001. Disponível em: http://www.planalto.gov.br/ccivil 03/leis/leis 2001/110172.htm. Acesso em: 20 fev. 2017.

BRASIL. Ministério da Educação. Programa de Apoio a Planos de Reestruturação e Expansão das Universidades Federais - REUNI. Brasília, DF: Ministério da Educação, 2007a. Disponível em: http://www.planalto.gov.br/ccivil_03/_Ato20072010/2007/Decreto/D6096.htm. Acesso em 20 jan. 2017.

BRASIL. Ministério da Educação. O plano nacional de educação: razões, princípios e programas. Brasília, DF: Ministério da Educação, 2007b. Disponível em: http://portal.mec.gov.br/arquivos/livro/livro.pdf. Acesso em: 21 jan. 2017 
BRASIL. Ministério da Educação. Programa de Apoio a Planos de Reestruturação e Expansão das Universidades Federais: Reuni 2008 - Relatório de Primeiro Ano. Brasília, DF: Ministério da Educação, 2009. Disponível em: http://portal.mec.gov.br/index.php?option=com_docman\&view=download\&alias=2069-reunirelatorio-pdf\&category_slug=dezembro-2009-pdf\&Itemid=30192. Acesso em: 20 jan. 2017

CABRAL, A. C. de A. et al. Reestruturação e expansão do ensino superior público: o programa Reuni na Universidade Federal do Ceará sob a visão dos alunos. Revista do Serviço Público, Brasília, v. 62, n. 3, p. 297-319, 2011.

CALDERÓN, A. I.; BORGES, R. M. Avaliação educacional: uma abordagem à luz das revistas científicas brasileiras. Revista Iberoamericana de Evaluación Educativa, Madrid, v. 6 , n. 1 , p. 167-183, 2013.

DIAS SOBRINHO, J. Avaliação e transformações da educação superior brasileira (19952009): do provão ao Sinaes. Avaliação, Campinas; Sorocaba, v. 15, n. 1, p. 195-224, 2010.

DOURADO, L. F.; CATANI, A. M.; OLIVEIRA, J. F. de. Políticas públicas e reforma da educaçao superior no Brasil: impasses e perspectivas. Pró-posiçoes, Campinas, v. 15, n. 3, p. 91-115, 2004.

FARIA, C. A. P. de. A política da avaliação de políticas públicas. Revista Brasileira de Ciências Sociais, São Paulo, v. 20, n. 59, p. 97-110, 2005.

FARIA, C. A. P. de. Implementação: ainda o "elo perdido" da análise de políticas públicas no Brasil? Revista Debates, Porto Alegre, v. 6, n. 2, p. 13-36, 2012.

LIMA, E. E.; MACHADO, L. R. de S. Reuni e expansão universitária na UFMG de 2008 a 2012. Educação \& Realidade, Porto Alegre, v. 41, n. 2, p. 383-406, 2016.

LIMA, L. L.; D’ASCENZI, L. Implementação de políticas públicas: perspectivas analíticas. Revista de Sociologia e Política, Curitiba, v. 21, n. 48, p. 101-110, 2013.

MARTONI, V. B. M.; FERRAZ, D. L. da S. “Expansão para quem?”: uma análise dos objetivos do Reuni e das diretrizes para a educação do Banco Mundial. In: ENCONTRO DA ANPAD - EnANPAD, 37., 2013. Anais [...]. Rio de Janeiro: ANPAD, 2013. p. 1-16.

MEDEIROS, M. D. L. et al. Administração e políticas públicas em educação: uma revisão sistemática da produção do EnANPAD e EnAPG de 1997 a 2009. Revista de Ciências da Administração, Florianópolis, v. 13, n. 30, p. 61-87, 2011. 
MORAES, M. C. B.; AMBONI, N.; KALNIN, G. F. Produção acadêmica em avaliação do ensino superior no Brasil. Avaliação, Campinas; Sorocaba, v. 22, n. 03, p. 697-717, 2017.

OLIVEIRA, A. J. de et al. Programa Reuni nas instituições de ensino superior federal [IFES] brasileiras: um estudo da eficiência operacional por meio da análise envoltória de dados [DEA] no período de 2006 a 2012. Revista de Administração, Contabilidade e Economia, Joaçaba, v. 13, n. 3, p. 1179-1210, 2014.

POLIDORI, M. M. Políticas de avaliação da educação superior brasileira: Provão, SINAES, IDD, CPC, IGC e...outros índices. Avaliação, Campinas; Sorocaba, v. 14, n. 2, p. 439-452, 2009.

RAMOS, M. P.; SCHABBACH, L. M. O estado da arte da avaliação de políticas públicas: Conceituação e exemplos de avaliação no Brasil. Revista de Administração Pública, Rio de Janeiro, v. 46, n. 5, p. 1271-1294, 2012.

ROTHEN, J. C. et al. A divulgação da avaliação da educação na imprensa escrita: 1995-2010. Avaliação, Campinas; Sorocaba, v. 20, n. 3, p. 643-664, 2015.

SECCHI, L. Políticas públicas: conceitos, modelos de análise, casos práticos. São Paulo: Cengage Learning, 2011.

SERAFIM, M. P.; DIAS, R. de B. Análise de política: uma revisão da literatura. Cadernos Gestão Social, Salvador, v. 3, n. 1, p. 121-134, 2012.

TREVISAN, A. P.; VAN BELLEN, H. M. Avaliação de políticas públicas: uma revisão teórica de um campo em construção. Revista de Administração Pública, Rio de Janeiro, v. 2, n. 3, p. 529-550, 2008. 